\title{
Pulmonary embolism guidelines: will they work?
}

\section{A C Miller, D A R Boldy}

Updated guidelines on the management of suspected acute pulmonary embolism are published in this issue of Thorax. CT pulmonary angiography has become the central imaging investigation in the diagnosis of pulmonary embolism, but it is important that its use is carefully controlled to avoid unnecessary investigations in overworked radiology departments.

$\square$ wo years ago several members of the British Thoracic Society independently suggested that, in the light of recent publications, the Standards of Care Committee should update their 1997 advice on suspected acute pulmonary embolism (PE). This issue of Thorax contains the results of this endeavour, with evidence sufficiently robust now to allow these to be called guidelines (see pp 470-83). Those familiar with the previous publication, to which the new document frequently refers, will recognise that the same basic structure has been used.

Previously, the main recommended option in the face of a non-diagnostic ventilation-perfusion (V/Q) scan was pulmonary angiography, an invasive test that was little used before and probably little more after. This advice has been made redundant by developments in CT pulmonary angiography (CTPA), with strong evidence that, even though a negative result may not entirely exclude $\mathrm{PE}$, it does make anticoagulation unnecessary. There is no doubt that CTPA should now be considered the central imaging investigation in suspected $\mathrm{PE}$, and many acute hospitals are developing experience of the techniques.

However, this adds a considerable workload to radiology departments already struggling to cope with the increased imaging requirements for cancer staging, not helped by the fact that PE is confirmed in only $20-35 \%$ of those where it has been suspected. This has led to different strategies for reducing the number of unnecessary CTPAs, but these too have their problems.

Some hospitals continue to use V/Q scanning as a way of obtaining a definite answer, but $30-50 \%$ of such patients will require CTPA anyway, which delays definitive investigations and lengthens hospital stay, and others do not have nuclear medicine on site. Indeed, were CTPA easily and rapidly available, V/Q scanning would become largely obsolete.

"There is no doubt that CTPA should now be considered the central imaging investigation in suspected $\mathrm{PE}^{\prime \prime}$

Another approach is to restrict CTPA to patients who do not have the combination of low clinical probability and a negative D-dimer test. Since this halves the number requiring lung imaging it is an attractive option, but practical experience shows that there are pitfalls. Firstly, although the 1997 clinical probability assessment system has been retained (now on good evidence), the fact that it is very simple does not mean that junior doctors use it properly, as many senior clinicians and radiologists have discovered. Secondly, the seductive simplicity and low cost of D-dimer assays mean that, in many emergency departments, the test is done on a high proportion of patients who arrive with chest pain and/or breathlessness, even when another diagnosis is obvious, similar to the way that cardiac enzymes are often misused. The end result is that, where the D-dimer test happens to be positive, it is assumed that this makes PE more likely after all.

For these guidelines to work in practice without widespread abuse of the recommendations, the following policies should be introduced:

(1) Clinical probability must be recorded in the admission notes and be included on every request form for CTPA, a policy that would be fruitful to audit regularly.

(2) D-dimer tests may only be requested by junior doctors with at least 6 months post-registration experience of acute medicine. They should not be performed when CTPA is required anyway.

(3) Request forms for CTPA which do not state clinical probability and (where appropriate) D-dimer results are automatically rejected by the radiology department, accompanied by a strong telephone message.

(4) Where V/Q scanning remains part of the hospital's management algorithm, there should be a system in place whereby an inconclusive result leads to an automatic CTPA on the same day, without a further request having to be generated by the clinician.

(5) There should be at least one interested physician and radiologist who together review and refine both the hospital's policy and its application in practice.

These principles might appear draconian and unenforceable, yet several hospitals have been adopting them successfully for some time, finding that they stimulate good clinical thinking, reduce the number of unnecessary imaging tests, speed up the process of reaching a correct diagnosis, and are educationally valuable. Indeed, with the widespread changeover from unfractionated to low molecular weight heparin, an increasing number of patients are being quickly investigated and, where necessary, managed without being hospitalised.

Although the document is aimed primarily at junior physicians in UK Accident \& Emergency departments, almost all the underpinning evidence comes from continental Europe and North America. Allowing for variations in resources, organisation and clinical practice in different countries and debates around interpretation of current data, it broadly reflects current international thinking and should prove useful elsewhere.

Thorax 2003;58:463

\section{Authors' affiliations}

A C Miller, Chairman, BTS Pulmonary

Embolism Working Party

D A R Boldy, Chairman, BTS Standards of Care Committee

Correspondence to: $\operatorname{Dr}$ A C Miller, Mayday Hospital, Croydon CR7 7YE, UK

andrew.miller@mayday.nhs.uk 


\section{Nicotine replacement therapy in smoking cessation}

\section{Campbell}

\section{Evidence for benefit from nicotine replacement therapy in hospital patients is inconclusive, although the results of a trial reported in this issue of Thorax give cause for optimism and should stimulate further studies.}

M ost smokers become nicotine dependent and, when they stop smoking, experience withdrawal symptoms and craving. Nicotine replacement therapy (NRT) reduces these unpleasant symptoms and, theoretically, should decrease the risk of relapse. Smoking cessation is properly defined as validated sustained abstinence from cigarettes and/or other tobacco products for at least 6 months, but preferably for 1 year. This editorial includes evidence only from those studies which have applied such a definition and which have specified their settings and populations.

NRT is available as chewing gum, transdermal patches, sublingual tablets, lozenges, inhalation cartridges and nasal spray. In specialised cessation clinics ${ }^{1-8}$ and in primary care, ${ }^{9}{ }^{10}$ prospective randomised clinical trials have shown that NRT, used as an adjunct to advice and support, results in better cessation rates than does advice and support alone. In the clinics success rates with NRT tend to be higher (11-30\%) and more consistent than in primary care, where some studies have found no significant difference from placebo. ${ }^{11-14}$ One study in primary care showed $8 \%$ success with nicotine chewing gum compared with $4 \%$ with advice plus leaflet, but there was no placebo controlled arm. ${ }^{15}$ Two studies of transdermal nicotine in primary care have shown success rates of around 10\%, which were superior to those with placebo (around 6\%). ${ }^{9}$ The benefit for transdermal nicotine in cessation clinics $^{6-8}$ and in primary care ${ }^{910}$ is thus clear, whereas nicotine chewing gum, ${ }^{1-5}$ inhaler, $^{16}{ }^{17}$ nasal spray, $^{418}$ and lozenges $^{20}$ have only proved superior to placebo in cessation clinics. Success rates of 15-28\% have been reported with nicotine inhaler compared with 5-18\% with placebo, ${ }^{161721}$ the differences being significant in the first two studies but not in the third. Success rates with the nasal spray were higher than placebo in three studies $\quad(27 \%$ compared with $10-15 \%)^{4} 1819$ but not in a fourth. ${ }^{22}$ Sublingual tablets were more effective than placebo at 6 months but not at 12 months in 247 smokers attending a department of oral and maxillofacial surgery. ${ }^{23}$ Combinations of NRT have not usually done better than single versions, $^{21}{ }^{24-26}$ but Blondal et al showed that prolonged treatment with nicotine patches ( 5 months) and nasal spray ( 12 months) produced better results than nicotine patches alone. ${ }^{27}$ In a comparison of dosages, the large European CEASE trial reported a greater effect with a $25 \mathrm{mg}$ patch (15.4\% success) than with $15 \mathrm{mg}(13.7 \%$ success, $\mathrm{p}<0.03),{ }^{8}$ but in the USA Jorenby et $a l^{28}$ found that a $44 \mathrm{mg}$ patch did no better than $22 \mathrm{mg}$. The 24 hour patch and the 16 hour patch produced similar quit rates ${ }^{29}$; using the patch for 22 weeks rather than 8 weeks did not significantly improve the success rate. $^{8}$ In highly dependent smokers nicotine gum in a dosage of $4 \mathrm{mg}$ was better than $2 \mathrm{mg}^{30} ; 5-20 \%$ of smokers can become addicted to nicotine gum. ${ }^{31}{ }^{32}$ This appears to be less of a problem with transdermal nicotine ${ }^{33}$ and more of a problem with nasal spray. ${ }^{4}$ Unwanted effects have tended to result from local irritation but occasionally-usually in those who continue to smoke while on NRT-systemic effects of excessive nicotine can occur (chiefly nausea). ${ }^{16-182022232627}$ In pregnancy and in patients with myocardial infarction NRT, which delivers less nicotine than cigarettes and no carbon monoxide, is less hazardous than continued smoking but, nevertheless, there is still reluctance to use it.

NRT is now available in the UK on NHS prescription. Smoking cessation counsellors have been employed by the NHS to provide advice and support in the community to smokers who self-refer or are referred by other health professionals. NRT is usually offered as part of the package. The sustained validated 6 month or 1 year quit rates achieved through this service are eagerly awaited. These results should not only inform local health groups, primary care trusts, and government of how cost effective the service has proved and how best to shape it in future, but should also make an interesting comparison with the results obtained in the clinical trials. ${ }^{1-33}$

For hospital inpatients and outpatients the evidence for the efficacy of NRT as an adjunct to advice and support is not convincing. Many reports stemming from cessation services located in hospitals have been wholly or partly based on populations of self-referred smokers or smokers recruited via the media. Such populations differ in motivation and other aspects from patients who, despite presenting to secondary care services, continue to smoke. Their quit rate should not therefore be taken as representing the quit rates of populations of patients. The first randomised trial of NRT in hospital patients in the UK enrolled 1550 inpatients or outpatients with smoking related diseases (SRDs); neither nicotine chewing gum nor its placebo significantly improved on the success rate of $9 \%$ achieved by brief advice from the hospital physician and follow up in an outpatient clinic at 3, 6 and 12 months. ${ }^{34}$ This success rate is little different from the $11 \%$ reported from Nottingham by Molyneux et $a l^{35}$ in this issue of Thorax in a study of hospital inpatients which was not restricted just to those with SRDs. Interventions compared were: (a) usual care, (b) 20 minutes' bedside counselling by a research doctor or nurse trained in smoking cessation counselling plus an advice leaflet, and (c) 20 minutes' bedside counselling by the same personnel plus 6 weeks of NRT. Patients were allowed to choose one of five forms of NRT, 63\% electing transdermal nicotine. They were reviewed in outpatients or interviewed by telephone 3 and 12 months after entering the trial. Exhaled air carbon monoxide was used to validate claims of abstinence. In the usual care group 7.6\% were classed as successes (continuous abstinence) compared with $4.4 \%$ in those receiving counselling plus advice leaflet and $11 \%$ in the counselling plus NRT group $(p=0.25)$. Thus, like a previous trial by Campbell et $a l^{36}$ of transdermal nicotine plus counselling in 234 hospital outpatients and inpatients with SRDs which showed $21 \%$ success with active versus 14\% with placebo patches $(p=0.15)$, there was a suggestion that NRT was of benefit but smaller than expected sample sizes have limited the power to detect differences caused by treatment rather than chance.

Previous trials of NRT and counselling in hospital patients with SRDs have included a group given NRT placebo, ${ }^{34}{ }^{36-38}$ a design feature missing in the Nottingham study. Nicotine chewing gum was no more effective (20\% success) than placebo in a study of 219 inpatients, ${ }^{37}$ nor was transdermal nicotine (14\% success) better than placebo in 584 outpatients with ischaemic heart disease. $^{38}$ In a more recent outpatient 
trial conducted among 245 hospital inpatients and outpatients but excluding patients with recent myocardial infarction, advice and support plus the combination of regular transdermal nicotine and as required nicotine inhalator resulted in a success rate of $16 \%$ compared with $14 \%$ for advice and support alone. ${ }^{39}$ Higher success rates have been achieved in the hospital trials which provided more intensive support during the first weeks after quitting than was provided in the Nottingham trial. For hospital patients the evidence for benefit from NRT as an adjunct to advice and support (minimal or intensive) remains inconclusive, although the trial by Molyneux et al gives cause for optimism.

Guidance on the use of NRT and bupropion for smoking cessation was issued by the National Institute of Clinical Excellence (NICE) in March 2002. ${ }^{40}$ It is likely that UK hospitals will appoint smoking cessation counsellors to provide advice and support in conjunction with NRT or bupropion, as recommended by NICE. It is important not only that the success rates of these programmes be properly evaluated, but also that there should be further placebo controlled clinical trials of NRT in hospital patients. Such trials are both justified and desirable.

\section{Thorax 2003;58:464-465}

\section{Author's affiliation}

I Campbell, Llandough Hospital, Penarth, Cardiff CF64 2XX, UK;

ian.campbell@cardiffandvale.wales.nhs.uk

\section{REFERENCES}

1 Raw M, Jarvis $\mathrm{W}$, Feyerabend C, et al. Comparison of nicotine chewing-gum and psychological treatments for dependent smokers. BM 1980;281:481-4.

2 Jarvis MJ, Raw M, Russell MAH, et al. Randomised, controlled trial of nicotine chewing-gum. BM 1982;285:537-40.

3 Hialmarson AIM. Effect of nicotine chewing gum in smoking cessation: a randomised placebo-controlled, double-blind study. JAMA 1984:252:283-8.

4 Sutherland G, Stapleton JA, Russell MAH, et al. Randomised, controlled trial of nasal nicotine spray in smoking cessation. Lancet 1992;340:324-9.

5 Okuyemi KS, Jasjit SA, Harris KJ.

Pharmacotherapy of smoking cessation. Arch Fam Med 2000;9:270-81.

6 Tonnesen P, Norregard J, Simonsen K, et al. A double-blind trial of a 16 hour transdermal nicotine patch in smoking cessation. N Engl J Med 1991;325:311-5.

7 Westman EC, Levin ED, Rose JE. The nicotine patch in smoking cessation - a randomised trial with telephone counselling. Arch Intern Med 1993:153:1917-23.

8 Tonnesen P, Paoletti P, Gustavsson G, et al, on behalf of the European Respiratory Society. Higher dosage nicotine patches increase 1-year smoking cessation rates: results from the European CEASE trial. Eur Respir J $1999 ; 13: 238-46$

9 Imperial Cancer Research Fund General Practice Research Group. Effectiveness of the nicotine patch in helping people stop smoking: results of a randomised trial in general practice. BN 1993;306:1304-8.

10 Russell MAH, Stapleton JA, Feyerabend C, et al. Targeting heavy smokers in general practice: a randomised, controlled trial of transdermal nicotine patches. $B M$ 1993;306:1308-12

11 Jamrozik K, Fowler G, Vessey M, et al. Placebo controlled trial of nicotine chewing gum in general practice. $B M$ 1984;289:794-7

12 Marshall A, Raw M. Nicotine chewing gum in general practice: effect of follow-up appointment. BM 1985;290:1397-8.

13 Campbell I A, Lyons E, Prescott RJ. Stopping smoking: do nicotine chewing-gum and postal encouragement add to doctors' advice? Practitioner 1987;231:114-7.

14 Richmond RL, Makinson RJ, Keyhoe LA, et al. One-year evaluation of three smoking cessation interventions administered by general practitioners. Addict Behav 1993; 18:187-99.

15 Russell MAH, Merriman R, Stapleton J, et al. Effect of nicotine chewing gum as an adjunct to general practitioners' advice against smoking. BM 1983;287:1782-5.

16 Tonnessen P, Norregaard J, Mikkelsen K, et al. A double-blind trial of a nicotine inhaler in smoking cessation. JAMA 1993;269:1268smo

17 Hialmarson A, Nilsson F, Sjostrom L, et al. The nicotine inhaler in smoking cessation. Arch Intern Med 1997;157:1721-8.

18 Hiarmarson A, Franzom M, Westin A, et al. Effect of nicotine nasal spray on smoking cessation: a randomised, placebo controlled double-blind study. Arch Intern Med 1994; 154:2567-72.

19 Schneider NG, Olmstead R, Mody FV, et al. Efficiency of a nicotine nasal spray in smoking cessation: a placeo-controlled, double-blind trial. Addiction 1995;90: 1671-82.

20 Shiffman S, Dresler CM, Hajek P, et al. Efficacy of a nicotine lozenge for smoking. Arch Intern Med 2002;162:1267-76.

21 Tonnessen P, Mikkelsen KL. Smoking cessation with four nicotine replacement regimes in a lung clinic. Eur Respir J 2000;16:717-22

22 Blondal T, Franz M, Westin A. A double-blind trial of nicotine nasal spray as an aid in smoking cessation. Eur Respir J 1997; 10:185-90.

23 Wallstrom M, Nilson F, Hirsch JM. A randomised double-blind, placebo-controlled clinical evaluation of a nicotine sub-lingual tablet in smoking cessation. Addiction 2000;95:1161-71.

24 Kornitzer M, Boutsen M, Dramaix $M$, et al. Combined use of nicotine patch and gum in smoking cessation: a placebo-controlled clinical trial. Prev Med 1995;24:41-7.

25 Puska P, Korhonen HJ, Vartiainen E, et al. Combined use of nicotine patch and gum compared with gum alone in smoking cessation: a clinical trial in North Karelia. Tobacco Control 1995;4:231-5.

26 Hajek P, West R, Foulds J, et al. Randomised comparative trial of nicotine polacrilex, a transdermal patch, nasal spray and an inhaler. Arch Intern Med 1999;159:2033-8.

27 Blondal T, Gudmundsson L, Olafsdottir I, et al. Nicotine nasal spray or nicotine patch for smoking cessation: randomised trial with six year follow-up. BM 1999;318:285-9.

28 Jorenby DE, Smith SS, Fiore MC, et al. Varying nicotine patch dose and type of smoking cessation counselling. JAMA 1995; 274:1347-52.

29 Fiore MC, Smith SS, Jorenby DE, et al. The effectiveness of nicotine patch for smoking cessation. JAMA 1994:271:1940-7.

30 Silagy C, Lancaster T, Stead L, et al. Nicotine replacement therapy for smoking cessation (Cochrane Review). In: The Cochrane Library. Issue 4. Oxford: Update Software, 2002: 13

31 US Department of Health and Social Services. The health consequences of smoking: nicotine addiction: a report of the Surgeon General. DHHS publication (CDC) 88-406. Atlanta, GA: Centres for Diseases Control, Office on Smoking and Health, 1998.

32 Hughes JR, Gust SW, Keenan R, et al. Long term use of nicotine vs placebo gum. Arch Intern Med 1991:151:1993-8.

33 Fiore $M C$, Jorenby DE, Baker TB, et al. Tobacco dependence and nicotine patch: clinical guidelines for effective use. JAMA 1992;268:2687-94.

34 British Thoracic Society. Comparison of four methods of smoking withdrawal in patients with smoking-related diseases. $B M$ 1993;286:595-7.

35 Molyneux A, Lewis S, Leivers U, et al. Clinical trial comparing nicotine replacement therapy (NRT) plus brief counselling, brief counselling alone, and minimal intervention on smoking cessation in hospital inpatients. Thorax 2003:58:484-8.

36 Campbell I A, Prescott RJ, Tjeder-Burton SM. Transdermal nicotine plus support in patients attending hospital with smoking-related diseases: placebo-controlled study. Respir Med 1996:90:47-51.

37 Campbell IA, Tjeder-Burton SM, Prescott RJ. Smoking cessation in hospital patients given repeated advice plus nicotine or placebo chewing gum. Respir Med 1991;85:155-7.

38 Joseph AM, Norman SM, Ferry LH, et al. The safety of transdermal nicotine as an aid to smoking cessation in patients with cardiac disease. N Engl J Med 1996;335:1792-8.

39 Hand S, Edwards S, Campbell IA, et al. Controlled trial of three weeks nicotine replacement treatment in hospital patients also given advice and support. Thorax 2002;57:715-8.

40 National Institute for Clinical Excellence (NICE). Guidance on the use of nicotine replacement therapy (NRT) and bupropion for smoking cessation. Technology Appraisal Guidance No 39. London: NICE, March 2002. 


\section{ADAM 33: just another asthma gene or a breakthrough in understanding the origins of bronchial hyperresponsiveness?}

\section{S T Holgate, D E Davies, G Murphy, R M Powell, J W Holloway}

ADAM 33, the latest of the ADAM proteins to be described, has been identified as a major susceptibility gene in asthma linked to bronchial hyperresponsiveness. It provides an important breakthrough in our understanding of this complex disorder and its variable clinical and physiological presentations.

A thma is a disorder of the conducting airways in which Th2 mediated inflammation interacts with structural changes to cause variable airflow obstruction. Fundamental to disordered function is the concept of bronchial hyperresponsiveness (BHR) in which the airways constrict too much and too easily. In chronic severe asthma the inflammation and structural changes both become more intense ${ }^{1}$ and are paralleled by an increase in BHR that is only partially or non-responsive to treatment with corticosteroids. ${ }^{2}$ Explanations for BHR include mucosal and adventitial swelling causing a disproportionate reduction in airway calibre for a given degree of airways smooth muscle (ASM) shortening, ${ }^{3}$ excessive ASM shortening, ${ }^{4}$ an increase in ASM mass causing greater force generation, ${ }^{5}$ and an excessive velocity of contraction linked to altered crossbridge cycling. ${ }^{6}$ Morphometric studies have shown a graded increase in ASM mass in proportion to disease severity, and computer modelling has revealed that this and altered contractility are the most plausible explanations for BHR. ${ }^{5}$

\section{IDENTIFICATION OF A NEW ASTHMA RELATED GENE}

Asthma has a high heritability of up to $79 \%,{ }^{8}$ involving a few genes with moderate effects rather than many genes with small effects. . We have recently reported the first novel asthma related gene identified by positional cloning. ${ }^{10}$ A genome wide screen was undertaken using phenotypic data and DNA from 362 families in Wessex and 98 in the USA with at least two siblings with asthma. Using 401 microsatellite markers at a density of $9 \mathrm{cM}$ and multipoint linkage analysis, suggestive evidence for linkage (maximum lod score (MLS) 2.24) was found on the short arm of chromosome 20 at $9.99 \mathrm{cM}$. The addition of 13 more markers at $1-2 \mathrm{cM}$ intervals increased the MLS to 2.94 at D20S482 $(12.1 \mathrm{cM})$ which further increased to 3.93 when BHR was included in the definition of asthma (despite halving the sample size), thereby exceeding the threshold for genome wide significance. ${ }^{11}$ In contrast, when asthma was conditioned for serum total IgE and allergen specific IgE as measures of the allergic component of asthma, the MLS fell to 2.3 at $11.6 \mathrm{cM}$ and 1.87 at $12.1 \mathrm{cM}$. This indicated that the chromosomal region under the peak of linkage contained genes more closely linked to altered airway function than to measures of atopy. Confirmation for linkage on chromosome 20 has come from separate analysis of the UK and US families, ${ }^{10}$ and from two separate genome wide studies in other UK and US outbred populations. ${ }^{12} 13$

Physical mapping of the region under the peak of linkage on 20p13 and direct cDNA selection led to the identification of 40 genes. $^{10}$ Single strand conformational polymorphism (SSCP) analysis and direct sequencing was used to identify single nucleotide polymorphisms (SNPs) used for case-control association studies involving 130 affected individuals who contributed to the linkage signal on chromosome 20 and 217 controls with no personal or family history of either asthma or allergy — that is, "hypernormals". In 23 genes spanning the 90\% confidence interval on each side of D20S482, 135 SNPs were typed of which 25 were localised to a cluster of five genes showing significant association with both asthma and BHR. Fourteen of these lay within a single gene identified as
ADAM 33, a novel member of the ADAM (A Disintegrin And Metalloproteinase) family (achieving significance of $p=0.005-0.05)$. Both in the combined populations and in the UK and US samples when analysed separately, additional SNP typing strengthened the location of the signal to ADAM 33 and this was further confirmed both by haplotype analysis (5-7 SNP combinations at $\mathrm{p}=0.000003-0.005)$ and transmission disequilibrium testing (TDT) (8 SNP combinations at $\mathrm{p}<0.005)$. The association of SNPs in ADAM 33 with asthma has recently been confirmed in three different ethnic populations in the USA, one in Holland, ${ }^{14}$ and in separate casecontrol and family studies in Germany (M Wijst, personal communication).

\section{CHARACTERISTICS OF THE ADAM GENE FAMILY}

ADAM 33 is the most recently reported member of the ADAM gene family of $\mathrm{Zn}^{++}$ dependent matrix metalloproteases (MMPs). ADAMs have a complex organisation involving eight domains, the first six encoding signal sequence and pro-, catalytic, disintegrin, cysteine rich and EGF domains ${ }^{15}$ which are anchored at the cell surface or Golgi apparatus by a transmembrane domain, followed by a cytoplasmic domain with intracellular signalling specific sequences (fig 1). ADAM 33 belongs to the ADAM 12, 15 and 19 subfamilies, all of which possess proteolytic activity. ${ }^{15} 16$ Northern blot analysis identified two transcripts of ADAM 33 of 5.0 and $3.5 \mathrm{~kb}$, but only the latter has been found in cytoplasmic RNA. ${ }^{10}$ Seventeen cDNA libraries have been screened resulting in the identification of a $3.5 \mathrm{~kb}$ clone containing the entire open reading frame comprising 22 exons with the canonical sequence (CT/AG) present at each splice junction. The potential for alternatively spliced transcripts is also indicated by the identification of variants lacking exons, or parts of exons. ADAM 33 is preferentially expressed in smooth muscle, myofibroblasts and fibroblasts, but not in epithelial cells, $\mathrm{T}$ cells or inflammatory leukocytes. ${ }^{10}{ }^{17}$ The significance of ADAM 33 for asthma is strengthened by the existence of a syntenic region on mouse chromosome 2 at $74 \mathrm{cM}$ that has been linked to $\mathrm{BHR}^{18}$ overlying an orthologue of ADAM 33 that exhibits approximately $70 \%$ homology with its human counterpart. ${ }^{17} 19$

The selective expression of ADAM 33 in mesenchymal cells strongly suggests that alterations in its activity may underlie abnormalities in the function of ASM cells and fibroblasts linked to BHR in asthma. These components of the epithelial-mesenchymal trophic unit $(\text { EMTU })^{20}$ share a common fibroblastic progenitor, the mature phenotype of which is directed by growth factors, 


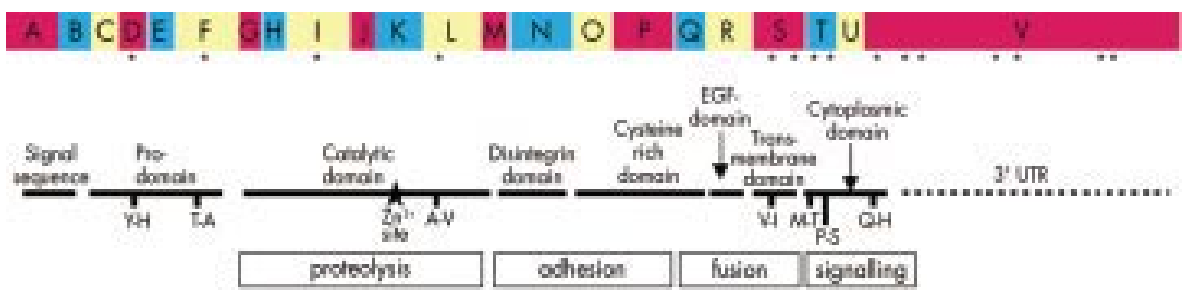

Figure 1 The exon structure and domain organisation of full length ADAM 33. The location of disease related SNPs in the coding and 3' untranslated regions are indicated by an asterisk and those SNPs leading to an amino acid change are also shown together with the likely functions of each domain. Reproduced with permission of Elsevier from Davies et al. ${ }^{22}$

including TGF- $\beta{ }^{21}{ }^{22}$ whose release from bronchial epithelial cells is increased in response to epithelial damage and airway inflammation. ${ }^{23}{ }^{24}$ Asthmatic (myo) fibroblast cells are unusual in that they have the capacity to proliferate in the absence of exogenous growth factors, ${ }^{21}{ }^{25}$ paralleling the behaviour of asthmatic ASM cells in vitro. ${ }^{26}$ This shared trait is consistent with the occurrence of a common stem cell population whose numbers are increased in asthma due to an inherent capacity for enhanced growth and/or survival.

Members of the ADAM family are proteins with diverse functions that reflect the complex domain structure of these molecules (fig 1). ${ }^{15}$ While certain functions can be attributed to an individual domain-for example, ectodomain shedding to the metalloproteinase domain ${ }^{27}$ and cell adhesion to the disintegrin domain ${ }^{28}$ - it is likely that the other domains play important regulatory roles in these functions by conferring specificity and selectivity. ADAM proteins are anchored in the trans-Golgi network or plasma membrane but, in some cases, secreted splice variants have been identified. In the case of ADAM 12, an evolutionarily close relative of ADAM 33, ectopic expression of the secreted form of the molecule (ADAM 12S) in rhabdomyosarcoma cells results in growth of tumour xenografts which are infiltrated with large numbers of host derived smooth muscle cells. ${ }^{29}$ Although we have identified several alternatively spliced forms of ADAM 33 in lung derived cDNA, it is not yet known whether a secreted protein variant is produced by airway cells.

The importance of genetic variation in ADAM proteins has recently been highlighted by mutations in ADAMTS13 (ADAM with thrombospondin type 1 motif) that underlie thrombotic thrombocytopenic purpura, ${ }^{30}$ while decreased levels of ADAMTS2 impair collagen type 1 processing leading to fragile skin in Ehlers-Danlos syndrome. ${ }^{31}$

\section{POSSIBLE ROLE OF ADAM 33 IN ASTHMA AND BHR}

Although ADAM 33 is a highly polymorphic gene containing over 55 SNPs, genetic analyses have identified the $3^{\prime}$ portion of the gene that encodes the transmembrane and cytoplasmic domains and 3'UTR as likely to be the key region linked to asthma and BHR. ${ }^{10}$ In the UK population association studies revealed that six SNPs in the ADAM 33 gene were significant at $p<0.03$, including two $\left(S_{1}\right.$ and $\left.S_{2}\right)$ in the exon encoding the transmembrane domain $(p=0.03$ and 0.004 , respectively) and another $\left(\mathrm{ST}_{+4}\right)$ which lies in the intron separating the transmembrane and cytoplasmic domains $(\mathrm{p}=0.02$, fig 1$)$. When $\mathrm{ST}_{2}$ and $\mathrm{ST}_{+4}$ were analysed as a haplotype or with SNPs in the intron preceding the V exon, the level of significance greatly increased $(p=0.000003-0.0005)$. Further confirmation that the transmembrane and intracellular domains are key sites for controlling altered functions of ADAM 33 comes from TDT analyses in the UK population. In this case the exonic S, SNP, which leads to an amino acid substitution $(\mathrm{V} \rightarrow \mathrm{l}$ (one letter code)), showed a significant association with asthma $(\mathrm{p}=0.0043)$ and BHR $(p=0.0066)$. Additional haplotype analysis increased the significance of the association of this SNP with asthma and BHR when taken in conjunction with the $\mathrm{T}_{1}$, an SNP which causes an amino acid substitution $(\mathrm{M} \rightarrow \mathrm{T})$ in the cytoplasmic domain, and with SNPs in the V exon encoding the end of the cytoplasmic domain and the $3^{\prime}$ UTR $(p=0.0001)$. Considering that the $\mathrm{S}_{1}$ and $\mathrm{T}_{1}$ SNPs occur in close proximity in the transmembrane and cytoplasmic domains of ADAM 33 and flank the intronic $\mathrm{ST}_{+4} \mathrm{SNP}$ (fig 1), polymorphisms in this region together with others in the 3'UTR may alter the activity of ADAM 33, conferring susceptibility to BHR and asthma. However, without further genetic and functional studies it is difficult to attribute primacy to any individual SNP because of the extent of linkage disequilibrium that exists in this region.

The cytoplasmic domains (CTD) of ADAM proteins are typically rich in proline and have important regulatory functions through their interaction with intracellular signalling proteins via $\mathrm{SH} 2$ and/or SH3 domains. Furthermore, the presence of alternatively spliced cytoplasmic variants of ADAM 22 have been shown to exhibit cell selective expression. Yeast two hybrid, western blotting, and pull down assays have identified several proteins that interact with the ADAMs, including src family kinases, endophilin, $\alpha$-actinin, PACSIN, and protein kinase $\mathrm{C}(\mathrm{PKC}) .^{27}{ }^{32-35}$ Together with the transmembrane domain, the CTD mediates interactions with the cytoskeleton and is involved in intracellular trafficking of the protein. ${ }^{36}$ For example, phosphorylation of ADAM 9 by PKC causes trafficking of the protein from the Golgi to the plasma membrane where it cleaves heparin binding EGF-like growth factor (HB-EGF) from its membrane bound precursor. ${ }^{27}$ In the case of ADAM 33, the intracellular domain is relatively short by comparison with its nearest homologues but it is very rich in prolines and has a putative $\mathrm{SH} 3$ binding site (P.WPLDP) in which the $\mathrm{T}_{2}$ SNP is located and may affect function. There is also a casein kinase F/II phosphorylation site (SHEPSSHP) and a MAPK consensus sequence which could be important regulators of ADAM 33 function. Although the $\mathrm{T}_{1}$ SNP causes an $\mathrm{M} \rightarrow \mathrm{T}$ substitution, no new recognisable phosphorylation site is generated.

ADAM 33 is amply provided with a number of other mechanisms whereby its disordered function could translate into BHR although, at this time, it is not clear whether changes in ADAM 33 linked to asthma relate to a gain or loss in function. ${ }^{37}{ }^{38}$ In many ADAMs the proteolytic site has the capacity to release cytokines and growth factors from their precursors. For example, ADAM17 (TNF $\alpha$ converting enzyme (TACE)) is responsible for generating both $\mathrm{TNF} \alpha$ and $\mathrm{TGF} \alpha{ }^{39}$ while ADAMs 9 and 12 cleave HB-EGF from its precursor. ${ }^{27}{ }^{28}$ In a mouse model of hypertension induced cardiac hypertrophy a pivotal role for myocardial ADAM 12 has been shown through its capacity to generate HB-EGF. ${ }^{40}$ Loss of function may lead to impaired processing of cytokines and growth factors. Reduced processing of myostatin, a member of the TGF- $\beta$ / BMP superfamily, is associated with differentiation into myotubes. ${ }^{41}$ Several of the ADAM family members are involved in cell-cell and cell-matrix interactions involving members of the integrin family, ${ }^{42}$ although binding to syndecans, ${ }^{43}$ members of the tetrapsanin family, and unknown proteins has also be shown. Binding of fibroblasts to a soluble ADAM 
9:Fc fusion protein via $\alpha_{6} \beta_{1}$ causes a very large increase in cell motility, which suggests that the ADAM could act as a locomotor adhesion receptor. ${ }^{44}$ In contrast, overexpression of ADAM 15 decreases cell migration by increasing cellcell contacts without affecting initial cell adhesion. ${ }^{45}$

In conjunction with the cysteine rich domain, a novel secreted form of ADAM 12 provokes myoblast fusion in vivo by binding to the muscle specific actin binding protein, $\alpha$-actinin-2.29 If the equivalent domain in ADAM 33 has similar properties, it could be implicated in converting ASM cells from acting as multiple units to a single contractile unit, ${ }^{46}$ a property relevant to the pathogenesis of BHR.

\section{CONCLUSIONS}

The identification of ADAM 33 as a major susceptibility gene in asthma linked to BHR is an important breakthrough in our understanding of this complex disorder and its variable clinical and physiological presentations. ${ }^{47}$ ADAM 33 is the latest of the ADAM proteins to be described, ${ }^{17}{ }^{19}$ with its implication in the pathogenesis of asthma being discovered in the same year. Identifying a major new candidate gene for asthma creates an imperative to determine its function and how disordered function translates into disease. The work ahead is likely to provide important insights into the origins and progression of asthma, especially since expression of ADAM 33 has now been shown in fetal lung tissue. It is not infrequently stated that searching the whole genome for susceptibility genes in complex diseases such as asthma is a fruitless "fishing expedition". However, as recently pointed out by Ahmadi and Goldstein ${ }^{47}$ a sequential approach to identifying novel genes in complex disorders by combining linkage and association approaches can achieve success without having to resort to expensive and time consuming genomewide association mapping. To achieve this in any complex disease it is becoming increasingly appreciated that it is essential to define the disease phenotype accurately. ADAM 33 can now be added to calpain 10 (type 2 diabetes) ${ }^{48}$ and NOD 2 (Crohn's disease $)^{49}$ as an entirely novel molecule linked to the pathogenesis of a complex human disease. The future challenge will be to determine the function(s) of ADAM 33 and the abnormalities that may occur to account for its association with asthma and BHR.

Thorax 2003;58:466-469

\section{Authors' affiliations}

S T Holgate, D E Davies, G Murphy, R M

Powell, J W Holloway, Southampton General

Hospital, Southampton, UK
Correspondence to: Professor S T Holgate, Southampton General Hospital, Southampton, UK; s.holgate@soton.ac.uk

\section{REFERENCES}

1 Carroll N, Lehmann E, Barret J, et al. Variability of airway structure and inflammation in normal subjects and in cases of nonfatal and fatal asthma. Pathol Res Pract 1996; 192:238-48.

2 Juniper EF, Kline PA, Vanzieleghem MA, et al. Effect of long-term treatment with an inhaled corticosteroid (budesonide) on airway hyperresponsiveness and clinical asthma in nonsteroid-dependent asthmatics. Am Rev Respir Dis 1990;142:832-6.

3 James AL, Pare PD, Hogg JC. The mechanics of airway narrowing in asthma. Am Rev Respir Dis 1989:139:242-6.

4 Wiggs BR, Moreno R, Hogg JC, et al. A model of the mechanics of airway narrowing. J Appl Physiol 1990; 69:849-60

5 Lambert RK, Wiggs BR, Kuwano K, et al. Functional significance of increased airway smooth muscle in asthma and COPD. J Appl Physiol 1993;74:2771-81

6 Fredberg JJ. Airway smooth muscle in asthma: flirting with disaster. Eur Respir J 1998;12:1252-6

7 Klinke DJ, Lewis AK, Wong S-P, et al. Airway hyperresponsiveness: exploration of mechanisms using a dynamic, computer-based model of asthma. Am J Respir Crit Care Med 2001;163:A832.

8 Duffy DL, Martin NG, Battistutta D, et al. Genetics of asthma and hay fever in Australian twins. Am Rev Respir Dis 1990;142:1351-8.

9 Jenkins MA, Hopper JL, Giles GG Regressive logistic modeling of familial aggregation for asthma in 7394 population-based nuclear families. Genet Epidemiol 1997; 14:317-32.

10 Van Eerdewegh P, Little RD, Dupuis J, et al. Association of the ADAM-33 gene with asthma and bronchial hyper-responsiveness. Nature 2002;418:426-30.

11 Kruglyak L, Lander ES. Genetic dissection of complex traits: guidelines for interpreting and reporting linkage results. Nature Genetics 1995;11:241-7.

12 Cookson WO, Ubhi B, Lawrence R, et al. Genetic linkage of childhood atopic dermatitis to psoriasis susceptibility loci. Nature Genet 2001;27:372-3.

13 Xu J, Meyers DA, Ober C, et al. Genomewide screen and identification of gene-gene interactions for asthma-susceptibility loci in three US populations: collaborative study on the genetics of asthma. Am J Hum Genet 2001;68:1437-46.

14 Howard TD, Meyers DA, Ampleford EA, et al. Association of ADAM33 with asthma and associated phenotypes in ethically diverse populations. Am J Hum Gen 2002;71:488.

15 Primakoff P, Myles DG. The ADAM gene family: surface proteins with adhesion and protease activity. Trends Genet 2000;16:83-7.

16 Black RA, White JM. ADAMs: focus on the protease domain. Curr Opin Cell Biol 1998; 10:654-9.

17 Yoshinaka T, Nishii K, Yamada K, et al. Identification and characterization of novel mouse and human ADAM33s with potential metalloprotease activity. Gene 2002;282:227-36.

18 De Sanctis GT, Merchant M, Beier DR, et al. Quantitative locus analysis of airway hyperresponsiveness in $\mathrm{A} / \mathrm{J}$ and $\mathrm{C} 57 \mathrm{BL} / 6 \mathrm{~J}$ mice. Nature Genet 1995;11:150-4.

19 Gunn TM, Azarani A, Kim PH, et al. Identification and preliminary characterization of mouse Adam33. BMC Genet 2002:3:2.

20 Holgate ST, Davies DE, Lackie PM, et al. Epithelial-mesenchymal interactions in the pathogenesis of asthma. J Allergy Clin Immunol 2000;105:193-204.

21 Richter A, Puddicombe SM, Lordan JL, et al. The contribution of interleukin (IL)-4 and IL-13 to the epithelial-mesenchymal trophic unit in asthma. Am J Respir Cell Mol Biol 2001;25:385-91

22 Davies DE, Wicks J, Powell RM, et al. Airway remodelling in asthma: new insights. J Allergy Clin Immunol 2003;1 11:215-22. (epub ahead of publication)

23 Zhang S, Smartt H, Holgate ST, et al. Growth factors secreted by bronchial epithelial cells control myofibroblast proliferation: an in vitro co-culture model of airway remodeling in asthma. Lab Invest 1999;79:395-405.

24 Puddicombe SM, Polosa R, Richter A, et al. Involvement of the epidermal growth factor receptor in epithelial repair in asthma. FASEB J 2000;14:1362-74.

25 Chaudhary N, Richter A, Collins JE, et al. Phenotype comparison of asthmatic and nonasthmatic (Myo)fibroblasts. Am J Respir Crit Care Med 2001;163:A473

26 Johnson PR, Roth $M$, Tamm M, et al. Airway smooth muscle cell proliferation is increased in asthma. Am J Respir Crit Care Med 2001; 164:474-7.

27 Izumi Y, Hirata M, Hasuwa $H$, et al. A metalloprotease-disintegrin, MDC9/meltrin-gamma/ADAM9 and PKCdelta are involved in TPA-induced ectodomain shedding of membrane-anchored heparin-binding EGF-like growth factor. EMBO J 1998;17:7260-72.

28 Nath D, Slocombe PM, Webster A, et al. Meltrin gamma(ADAM-9) mediates cellular adhesion through alpha(6)beta(1) integrin, leading to a marked induction of fibroblast cell motility. J Cell Sci 2000;113:2319-28.

29 Gilpin BJ, Loechel F, Mattei MG, et al. A novel, secreted form of human ADAM 12 (meltrin alpha) provokes myogenesis in vivo. $J$ Biol Chem 1998;273:157-66.

30 Levy GG, Nichols WC, Lian EC, et al. Mutations in a member of the ADAMTS gene family cause thrombotic thrombocytopenic purpura. Nature 2001;413:488-94.

31 Colige A, Sieron AL, Li SW, et al. Human Ehlers-Danlos syndrome type VII C and bovine dermatosparaxis are caused by mutations in the procollagen I N-proteinase gene. Am J Hum Genet 1999;65:308-17.

32 Howard L, Nelson KK, Maciewicz RA, et al. Interaction of the metalloprotease disintegrins MDC9 and MDC 15 with two SH3 domain-containing proteins, endophilin I and SH3PX 1. J Biol Chem 1999;274:31693-9.

33 Galliano MF, Huet C, Frygelius J, et al. Binding of ADAM12, a marker of skeletal muscle regeneration, to the muscle-specific actin-binding protein, alpha -actinin-2, is required for myoblast fusion. J Biol Chem 2000;275: 13933-9.

34 Cousin H, Gaultier A, Bleux C, et al PACSIN2 is a regulator of the metalloprotease/disintegrin ADAM13. Dev Biol 2000;227: 197-210

35 Poghosyan Z, Robbins SM, Houslay MD, et al. Phosphorylation-dependent interactions between ADAM15 cytoplasmic domain and Src family protein tyrosine kinases. J Biol Chem 2002;277:4999-5007.

36 Hougaard S, Loechel F, Xu X et al. Trafficking of human ADAM 12-L: retention in the trans-Golgi network. Biochem Biophys Res Commun 2000;275:261-7.

37 Drazen JM, Weiss ST. Genetics: inherit the wheeze. Nature 2002:418:383-4

38 Shapiro SD, Owen CA. ADAM-33 surfaces as an asthma gene. N Engl J Med 2002;347:936-8

39 Peschon JJ, Slack JL, Reddy P, et al. An essential role for ectodomain shedding in mammalian development. Science 1998;282:1281-4.

40 Asakura M, Kitakaze M, Takashima S, et al. Cardiac hypertrophy is inhibited by antagonism of ADAM12 processing of HB-EGF: metalloproteinase inhibitors as a new therapy. Nature Med 2002;8:35-40.

41 Huet C, Li ZF, Liu HZ, et al. Skeletal muscle cell hypertrophy induced by inhibitors of metalloproteases; myostatin as a potential mediator. Am J Physiol Cell Physiol 2001;281:C1624-34. 
42 Nath D, Slocombe PM, Stephens PE, et al. Interaction of metargidin (ADAM-15) with alphavbeta 3 and alpha5betal integrins on different haemopoietic cells. J Cell Sci 1999:112:579-87.

43 Iba K, Albrechtsen R, Gilpin B, et al. The cysteine-rich domain of human ADAM 12 supports cell adhesion through syndecans and triggers signaling events that lead to betal integrin-dependent cell spreading. J Cell Biol 2000;149: 1143-56.

44 Chen MS, Tung KS, Coonrod SA, et al. Role of the integrin-associated protein CD9 in binding between sperm ADAM 2 and the egg integrin alpha6betal: implications for murine fertilization. Proc Natl Acad Sci USA 1999:96:11830-5.

45 Herren B, Garton KJ, Coats S, et al. ADAM 15 overexpression in NIH3T3 cells enhances cell-cell interactions. Exp Cell Res 2001;271:152-60.

46 Hirst SJ. Airway smooth muscle cell culture: application to studies of airway wall remodelling and phenotype plasticity in asthma. Eur Respir J 1996;9:808-20.

47 Ahmadi KR, Goldstein DB. Multifactorial diseases: asthma genetics point the way. Curr Biol 2002; 1 2:R702-4.

48 Horikawa Y, Oda N, Cox NJ, et al. Genetic variation in the gene encoding calpain-10 is associated with type 2 diabetes mellitus. Nature Genet 2000;26:163-75.

49 Hampe J, Grebe J, Nikolaus S, et al. Association of NOD2 (CARD 15) genotype with clinical course of Crohn's disease: a cohort study. Lancet 2002;359:1661-5.

\section{LUNG ALERT}

\section{Allergic sensitisation to peanut may occur through inflamed skin}

$\Delta$ Lack G, Fox D, Northstone K, Golding J. Factors associated with the development of peanut allergy in childhood. $N$ Engl J Med 2003;348:977-85

The increasing incidence of peanut allergy prompted this group to look at the predispos-

ing factors to the condition. A subgroup of 49 children with a clear history of peanut

allergy was identified from the Avon longitudinal study (a cohort of 13971 preschool children). Information was obtained from questionnaires, medical records, and cord blood. Peanut allergy was confirmed by double blind, placebo controlled food challenge in 23 of the 36 children tested. Allergic responses to food challenge included bronchospasm, stridor, and angioedema. Significant associations with peanut allergy were found with soy milk/formula consumption (odds ratio 2.6), family history, and history of atopy. Interestingly, rashes over joints (odds ratio 2.6) and the use of skin preparations containing peanut oils to these rashes (odds ratio 6.8) were associated with peanut allergy. The group hypothesised that allergic sensitisation occurs to peanut antigens through inflamed skin as they are present in emollients used for the treatment of diaper rashes, eczema, dry skin, and inflammatory cutaneous conditions. More trials are needed, however, and, if this is the case, avoidance of exposure to emollients containing peanut oils may prove to be a cost effective therapeutic intervention. 